\section{L'Arxiu Arqueològic de Lleida: un nou espai per a la difusió del patrimoni arqueològic de la ciutat}

\section{Isabel Gil Gabernet}

Els orígens de l'Arxiu Arqueològic de Lleida es remunten als anys vuitanta del segle xx quan l'Ajuntament va començar a invertir recursos econòmics $i$ humans en el coneixement i la protecció del patrimoni arqueològic de la ciutat. Amb diverses col-laboracions entre l'Ajuntament, el Servei d'Arqueologia de la Generalitat i l'aleshores Estudi General de Lleida es van dur a terme les primeres excavacions arqueològiques rigoroses en indrets com el soterrani de la Paeria, l'església de Sant Martí o l'antic portal de Magdalena. Aquestes intervencions, a més de la seva aportació al coneixement de l'evolució històrica de la ciutat, van generar materials i documentació que formarien part del fons de l'arxiu arqueològic, en aquells moments, sota la tutela del recentment creat Servei d'Arqueologia de la Generalitat.

L'any 1992 es va consolidar l'aposta de l'Ajuntament pel patrimoni arqueològic de Lleida amb la creació d'una plaça d'arqueòloga municipal, primer pas en la gestació de la Secció d'Arqueologia de l'Ajuntament que va culminar l'any 2007 amb la consolidació de l'equip tècnic actual.

Des de l'inici de la seva creació, per delegació de la Generalitat de Catalunya i sota el paraigua de la normativa municipal, la Secció d'Arqueologia s'ha fet càrrec de la documentació, investigació i salvaguarda del patrimoni arqueològic de la ciutat, entesa aquesta com un jaciment únic, i dels diferents jaciments del seu terme municipal. Du a terme les intervencions arqueològiques, gestiona i custodia l'arxiu arqueològic que aquestes han generat, sense oblidar les tasques de difusió, tant científica con divulgativa.

Després del pas per diferents magatzems l'any 2009 es va construir la seu definitiva de l'arxiu. L'equipament situat a l'edifici Albarés, disposa a la planta soterrània d'un magatzem, un espai de més de $900 \mathrm{~m}^{2}$ expressament dissenyat i adaptat per a contenir les restes del passat recuperades a les excavacions fetes a la ciutat i el seu terme. A la planta superior hi ha l'oficina tècnica, la sala de neteja i classificació de materials i l'arxiu de la documentació generada per les intervencions. L'edifici, compartit amb una escola bressol i una ludoteca, disposa també d'una sala comuna polivalent on realitzar els tallers i altres activitats de difusió.

La crisi econòmica dels nou darrers anys ha suposat una dràstica reducció de l'activitat constructora a la ciutat i per tant la davallada en el nombre d'intervencions arqueològiques preventives realitzades al seu nucli històric i a la resta del terme municipal. Aquest fet ha permès dedicar més esforços i recursos als diferents canals de difusió utilitzats des de l'arxiu arqueològic, posant l'accent en aquells adreçats al ciutadà en general i a la població escolar en particular.

Des de l'any 2012 es programen cada diumenge visites guiades a les sales amb restes arqueològiques museïtzades dins del programa "Diumenges de Portes Obertes", que permeten visitar les restes de la casa romana de l'Auditori, les muralles medievals del carrer Anselm Clavé i les adoberies. Paral-lelament i des de finals del mateix any s'ofereixen a les escoles i IES de la ciutat dos tallers d'arqueologia, "Arqueòlegs, detectius del passat" i "Afrania, una esclava d'Ilerda", $\mathrm{i}$ visites guiades a les adoberies.

En el marc d'aquesta nova línia de difusió l'any 2014 es va inaugurar l'exposició "Retalls de nostra història” que va suposar l'obertura al públic del magatzem del propi arxiu arqueològic, amb l'adaptació didàctica d'una part del seu espai.

Finalment, l'any 2015 i ampliant l'espai del magatzem de l'arxiu dedicat a la difusió, es va crear el taller "Vine, i fes d'arqueòleg" on se simulen diferents tasques de l'activitat arqueològica, que inclou l'excavació d'un sorral amb restes ceràmiques i monedes de diferents èpoques històriques de la ciutat.

\section{Diumenges de portes obertes a les sales amb restes arqueològiques $\mathrm{i}$ al magatzem de l'Arxiu Arqueològic}

La legislació actual que regula la protecció del patrimoni arqueològic de Catalunya (Llei 9/1993, de 30 de setembre, del patrimoni cultural català $\mathrm{i}$ el Decret 78/2002, de 5 de març, del Reglament de protecció del patrimoni arqueològic i paleontològic) preveu, sempre que sigui possible, la conservació de les restes en el seu emplaçament original, al descobert o amb un rebliment temporal i en el seu defecte el seu trasllat o el rebliment definitiu. Regula també la seva eliminació en aquells supòsits en què donades les característiques de les restes no sigui possible o no es consideri adient la seva conservació, amb les pertinents actuacions prèvies necessàries per garantir la salvació dels seus valors culturals.

En el cas de Lleida, com d'altres ciutats on l'arqueologia urbana de prevenció ha permès un millor control sobre el seu patrimoni arqueològic, s'han aplicat diferents solucions buscant sempre l'equilibri entre la conservació in situ de les restes patrimonials i el desenvolupament urbanístic de la ciutat i el seu territori.

Així, a la ciutat podem trobar restes conservades al descobert en espais públics amb accés lliure com la muralla romana al Turó de la Seu Vella, la séquia de Torres a la canalització del riu i les recentment excavades restes del barri jueu. I exemples de restes conservades en espais privats com els murs de tancament andalusí i feudal de l'avinguda Blondel (actual soterrani del Zara) o el tram de la cuirassa de Porta Ferrissa de la Baixada de la Trinitat (Viatges Tabora) on s'ha de concertar amb els propietaris l'accés a les restes. Però cal destacar l'esforç fet des 
de l'Ajuntament en la museïtzació de diversos espais com les restes del soterrani de Paeria, les restes de l'església de Sant Joan, la domus romana de l'auditori, les adoberies de Lleida i les muralles medievals del carrer Anselm Clavé.

La divulgació d'aquest patrimoni conservat és una de les vies fonamentals per retornar a la ciutat les inversions fetes en les intervencions arqueològiques. Per promoure aquestes sales museïtzades es va dissenyar l'any 2008 "La Lleida secreta", una ruta arqueològica gestionada des de Turisme de Lleida, que després de diferents canvis actualment organitza una visita per grups que un mateix dia accedeix als soterranis de la Paeria, als absis de la plaça Sant Joan i a les muralles medievals, amb la possibilitat de canviar una de les tres sales per la visita a les adoberies.

I com dèiem, amb el programa de "Diumenges de portes obertes”, des de l'any 2012, l'Arxiu Arqueològic es va sumar a aquestes tasques de difusió amb visites guiades gratuïtes conduïdes pels arqueòlegs de l'Ajuntament a tres d'aquests espais i al propi magatzem de l'arxiu.

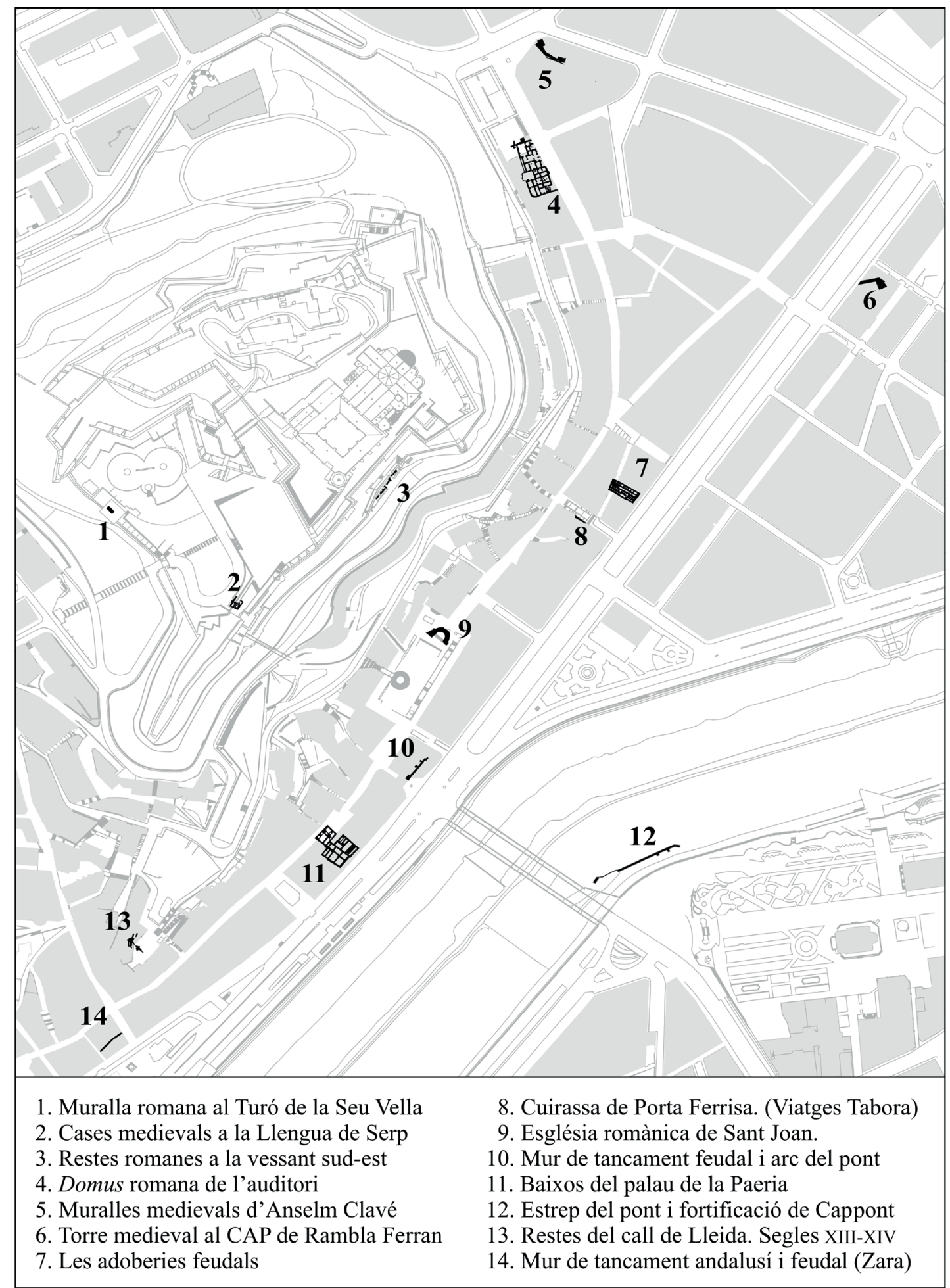

Figura 1. Plànol de situació de les restes arqueològiques conservades in situ que es poden visitar a la ciutat de Lleida. 


\section{La domus romana de l'auditori}

Els treballs arqueològics previs a la construcció de l'auditori-conservatori municipal i d'un pàrquing soterrani d'iniciativa privada a la plaça del mercat de l'Antic Portal de Magdalena, localitzada a l'extrem nordoccidental del nucli antic de la ciutat, van evidenciar la conservació d'una potent estratigrafia arqueològica en aquest indret. Això va provocar la renúncia a la construcció del pàrquing soterrani, convertint aquesta zona en una reserva arqueològica.

L'excavació en extensió de la superfície ocupada pel futur auditori, va suposar la major intervenció arqueològica que s'ha dut a terme a la ciutat. Durant tres anys, de 1984 a 1987, es van excavar $1.900 \mathrm{~m}^{2}$ amb una potència que oscil.lava entre els dos i sis metres. Es van documentar restes des d'època romana fins al segle XvıI de gran vàlua històrica i que van suposar una gran contribució al coneixement de l'evolució urbanística de la ciutat.

Finalitzada la intervenció es va decidir conservar les restes més antigues corresponents a una domus romana en una gran sala habilitada en el soterrani de l'auditori. Aquest gran edifici amb habitacions organitzades al voltant d'un atri, amb un pati i un hort fou construït a final del segle $\mathrm{I}$ dC i abandonat en la centúria següent.

La seva conservació va comportar la modificació del projecte arquitectònic de l'auditori amb la incorporació d'un soterrani, el desmuntatge i trasllat dels murs de la domus previ a la construcció de l'estruc- tura de l'auditori i el laboriós muntatge de nou in situ dels murs a l'interior del soterrani abans de la construcció dels forjats de l'equipament municipal.

L'auditori-conservatori es va inaugurar oficialment l'any 1995 i finalment la sala d'exposicions amb les restes de la casa romana es va adequar per a la seva visita l'any 2008, i va incorporar-se, en aquell moment, a la ruta de la Lleida secreta de Turisme. En l'actualitat les restes només es poden visitar dins del programa "Diumenges de portes obertes".

La visita consta de dues parts. En la primera, amb l'ajuda dels panells informatius s'explica la intervenció arqueològica a l'Antic Portal de Magdalena, la ciutat romana d'Ilerda, la mateixa domus, i a partir de les troballes que es van fer durant l'excavació es fa una aproximació al sentit religiós i a la vida quotidiana en el mon romà. Finalitza amb una explicació del complex procés que va suposar la conservació de la domus romana en el soterrani de l'edifici municipal.

La segona part de la visita correspon pròpiament a les restes de la domus, on malgrat la dificultat que comporta la seva comprensió, s'intenta mostrar els diferents àmbits de la gran casa i es poden apreciar les diferents tècniques constructives emprades.

Actualment per implementar aquesta visita $\mathrm{i}$ facilitar la comprensió de les restes conservades, des de l'arxiu s'està elaborant un audiovisual on de la mà d'Afrania, una lliberta que va viure a Ilerda al segle II dC, es fa un recorregut per la domus romana i la resta de la ciutat d'Ilerda que coneixem gràcies a les intervencions arqueològiques.

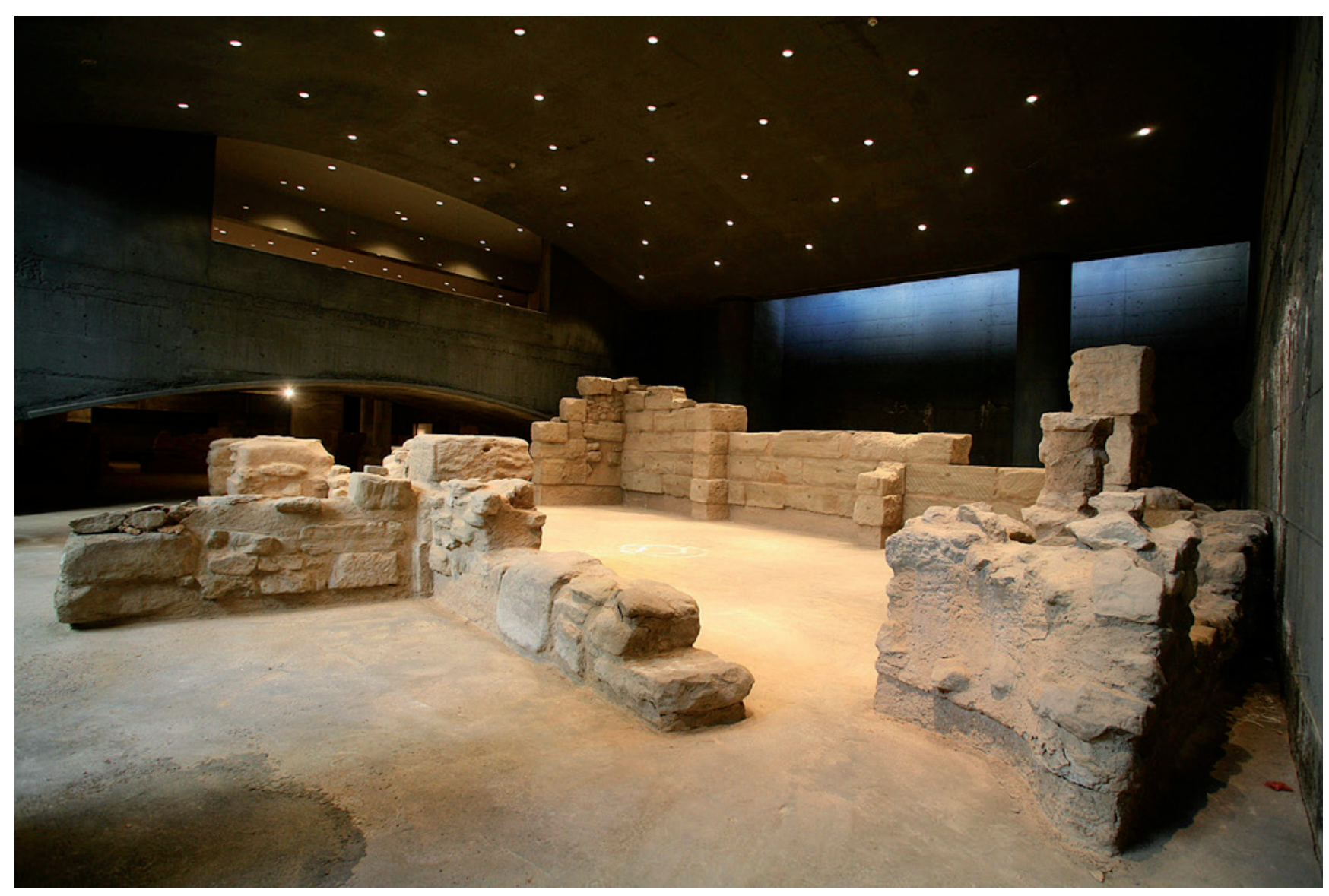

Figura 2. Vista del soterrani de l'auditori amb les restes conservades de la domus romana. 


\section{Les muralles medievals del carrer Anselm Clavé}

La intervenció arqueològica realitzada per la Secció d'Arqueologia de l'Ajuntament de Lleida al solar situat entre la plaça Mossèn Cinto Verdaguer i el carrer Anselm Clavé van permetre recuperar part de les antigues muralles de la ciutat.

El primer d'aquests tancaments està format per un tram de muralla lligat a dues torres de planta rectangular que formaven part de les fortificacions que protegien Madina Larida construïdes entre l'any 883 i el 884 dC. Aquest encintat murat perdurà en ús fins al segle XIV quan sota el regnat de Pere IV d'Aragó s'iniciaren importants obres de reparació i construcció de nous trams. És una muralla de 2,30 metres d'amplada feta amb dues cares de blocs rectangulars, que actuen d'encofrat d'un nucli de morter fet amb calç, grava i pedra de gran consistència. Aquesta estructura defensiva es recolza i utilitza de fonament l'antiga muralla andalusina.

Les tasques d'excavació es van prolongar del novembre de 1997 fins al juny de 1998, quan després de nou mesos d'excavacions i per acord de tots els actors implicats: Ajuntament, Servei de Patrimoni de la Generalitat i promotors, es va decidir finalitzar les tasques d'excavació ja que es renunciava a la construcció d'una segona planta de pàrquing. La solució final va implicar l'excavació fins als nivells geològics de la zona fora muralles, la realització de sondejos a l'interior i la construcció d'una llosa de formigó que segellava i convertia en reserva arqueològica la zona localitzada a l'interior de la muralla.

Es van desmuntar totes les restes per sobre del, nivell de la llosa de formigó per habilitar una primera planta de pàrquing i es va construir una sala soterrània davant de les muralles que es va cedir a l'Ajuntament a canvi d'una compensació edificable.

Pel que fa a les restes que configuren el tancament de la ciutat andalusina, com que la torre situada a l'angle nord-est de l'excavació quedava afectada per la construcció d'una sabata de l'edifici es va desmuntar bona part del basament de la torre andalusina i un cop finalitzada la construcció de la sabata i el pilar es van restituir els blocs de la torre en el seu estat original. Per la seva part la muralla feudal va quedar totalment integrada a l'estructura de l'edifici ja que suportava les càrregues de la llosa de formigó i del mateix edifici.

La sala cedida a l'Ajuntament, un cop museïtzada, fou inaugurada el 2007 i incorporada primer a la ruta de la Lleida secreta i posteriorment als Diumenges de portes obertes. Es tracta d'un espai amb un gran potencial didàctic que disposa d'un vestíbul on un panell a més de descriure les restes de les muralles conservades informa sobre el context històric de la construcció de les muralles que envoltaven la ciutat en època medieval (andalusina i feudal) i l'evolució urbanística de la ciutat.

En l'interior de la sala es poden veure els fonaments de dues torres de cinc metres d'amplada d'època andalusina fets amb grans blocs de pedra sorrenca disposats en filades del llarg i del través. El reforç d'una d'aquestes torres andalusines data del segle XII/ XIII i ocupa 32 metres lineals de la fonamentació de la muralla feudal del segle XIV, dividida en sengles trams de diferent orientació, que conserva entre dotze i sis filades d'alçada fetes amb blocs rectangulars de mida petita, alguns d'ells encoixinats.

La visita es completa amb un audiovisual elaborat per l'Arxiu Arqueològic: "Les muralles de Lleida: restes arqueològiques d'Anselm Clavé”. En tres apartats, en primer lloc es fa referència a les diferents fases arqueològiques que es van documentar en l'excavació del solar que van des de d'època romana fins al 1707, època que s'abandona aquesta part del barri de Magdalena. Després es fa referència al moment de desaparició de les muralles al segle XIX, quan l'arribada del ferrocarril a la ciutat provocà l'obertura de noves avingudes i la necessitat d'expansió, que comportà el progressiu enderroc de les muralles. Acaba amb un repàs a l'evolució de les diferents muralles documentades a la resta de la ciutat.

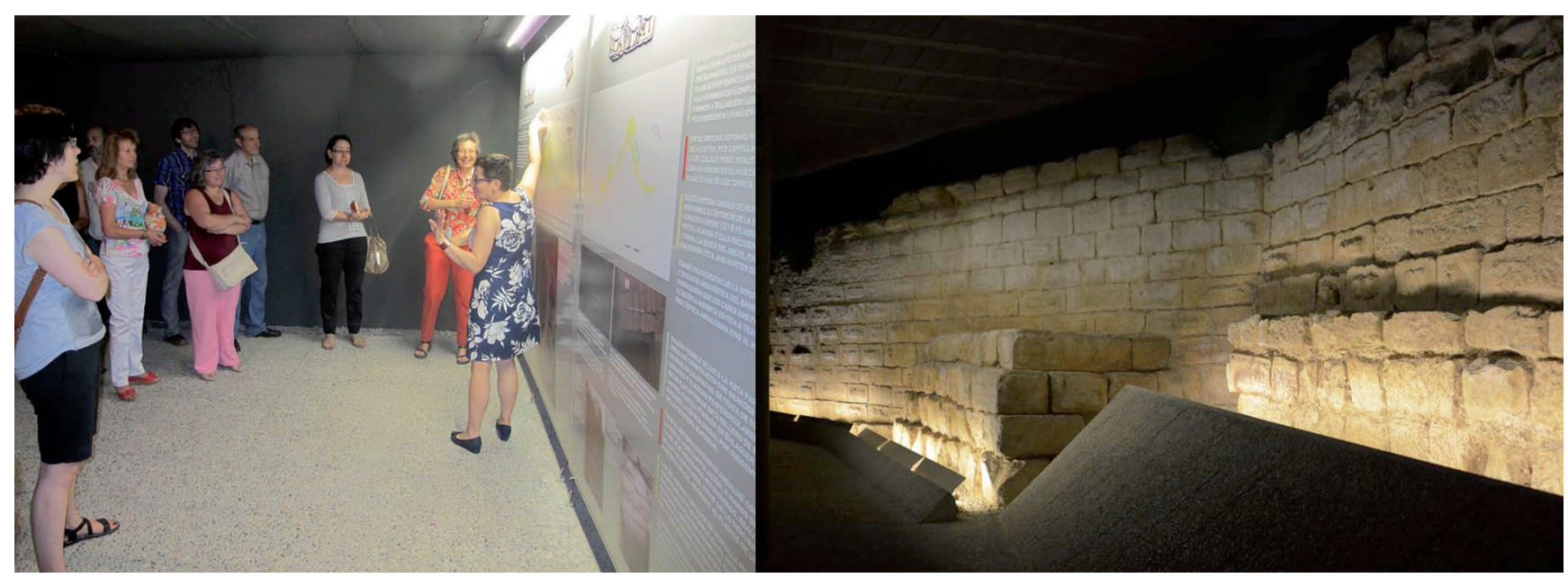

Figura 3. Vestíbul i sala amb les restes de les muralles medievals del carrer Anselm Clavé. 


\section{Les adoberies de Lleida}

En el número 9 de la rambla de Ferran es conserven in situ dos obradors dels sis que la Secció d'Arqueologia de l'Ajuntament va excavar entre els anys 2000 i 2006. L'excavació d'aquest solar va ser la darrera d'aquesta illa de cases que ha permès conèixer un dels conjunts adobers més antics i més ben conservats de l'Estat espanyol.

Després dels desafortunats precedents dels obradors localitzats entre els números de l'1 al 7 de la rambla de Ferran que van quedar sota una llosa de formigó, i donat l'immillorable estat de conservació d'aquests dos obradors, com a fruit d'un llarg i complex procés de negociacions entre Ajuntament i promotors es va acordar un lloguer amb opció de compra de la planta baixa de l'edifici.

L'any 2009 s'executà el projecte d'adequació i restauració de les adoberies, incorporant les tasques de museïtzació de les restes al conjunt d'obres finançades pel pla d'estímul d'ocupació municipal també conegut com "pla Zapatero". Projecte que incloïa un recorregut de visita per les restes i la utilització del vestíbul d'entrada per a serveis municipals permanents, on finalment es va instal-lar la seu de l'oficina del Pla de Barris Magdalena-Noguerola.

En la visita dels diumenges de portes obertes, aprofitant els panells informatius que s'han disposat en la zona del vestíbul s'explica al públic el laboriós procés de l'elaboració de les pells en època antiga, des del rentat de les pells arribades de l'escorxador fins al tintat final, passant per l'encalcinat i l'adob. Es fa també un repàs al diversos gremis relacionats amb el treball de la pell (adobers, assaonadors, blanquers, aluders, etc.) i la seva distribució per la ciutat.

A l'interior de la sala una passarel-la de fusta permet passar per sobre dels dos obradors i observar les restes històriques. En un dels laterals s'ha col-locat la restitució de com era el complex adober amb una representació de les sis adoberies construïdes a la primera meitat del segle XIII, que servei també per explicar el funcionament dels dos obradors conservats.

Però sense cap dubte un dels trets més destacable de la museïtzació d'aquesta sala és la recuperació del curs antic de l'aigua que feia funcionar les adoberies, i la conservació de la mina que, amb un origen per ara desconegut, conduiia l'aigua subterrània per sota dels edificis del carrer del Carme fins als obradors.

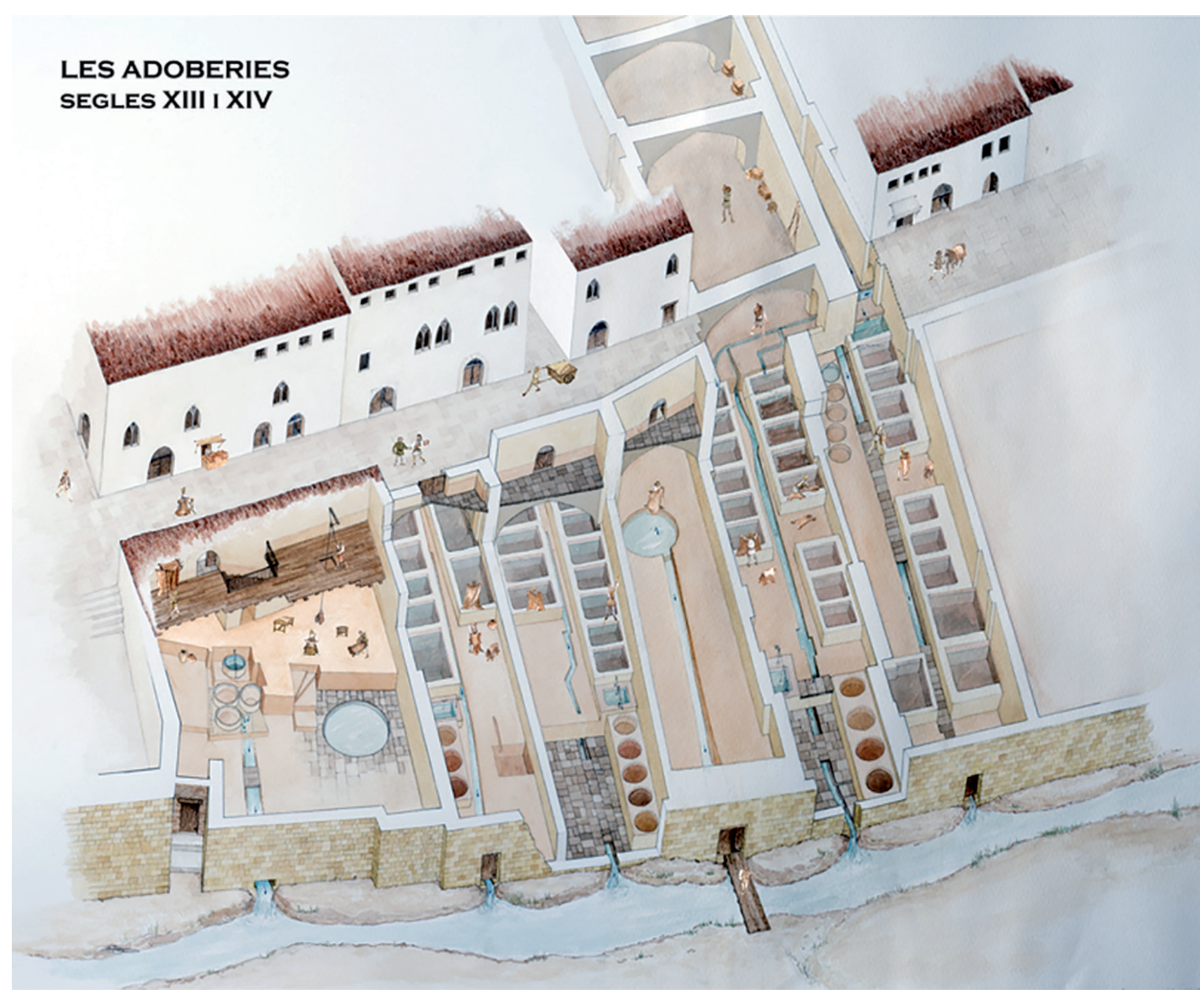

Figura 4. Restitució del complex adober de Lleida. Segle XIII (M. Molins). 


\section{El magatzem de l'Arxiu Arqueològic de Lleida}

Com hem assenyalat anteriorment, el magatzem de l'Arxiu Arqueològic és l'últim espai incorporat al programa de Diumenges de portes obertes. El 14 de setembre de 2014 l'associació de veïns de la Bordeta va inaugurar les visites al magatzem d'arqueologia que ha adaptat didàcticament una part del seu espai i on la mostra "Retalls de la nostra Història" permet un recorregut pels nombrosos materials de les diverses èpoques històriques que s'han recuperat en les excavacions de la ciutat i el seu terme municipal.

La gestació d'aquesta mostra va néixer al voltant de la necessitat d'un espai expositiu per al mosaic romà recuperat a les termes romanes del carrer Cardenal Remolins i per aquest motiu la primera part de l'exposició està centrada en el procés de restauració en general i del mosaic en particular. Un audiovisual amb la restitució en 3D i altres elements decoratius recuperats a l'edifici termal contextualitzen el fragment de mosaic exposat. Tanca aquest primer apartat un repàs per l'evolució dels banys al llarg de la història des de les termes romanes fins als spas actuals.

En les vitrines s'exposen algunes de les peces més significatives recuperades en les intervencions, que per la seva singularitat o bon estat de conservació

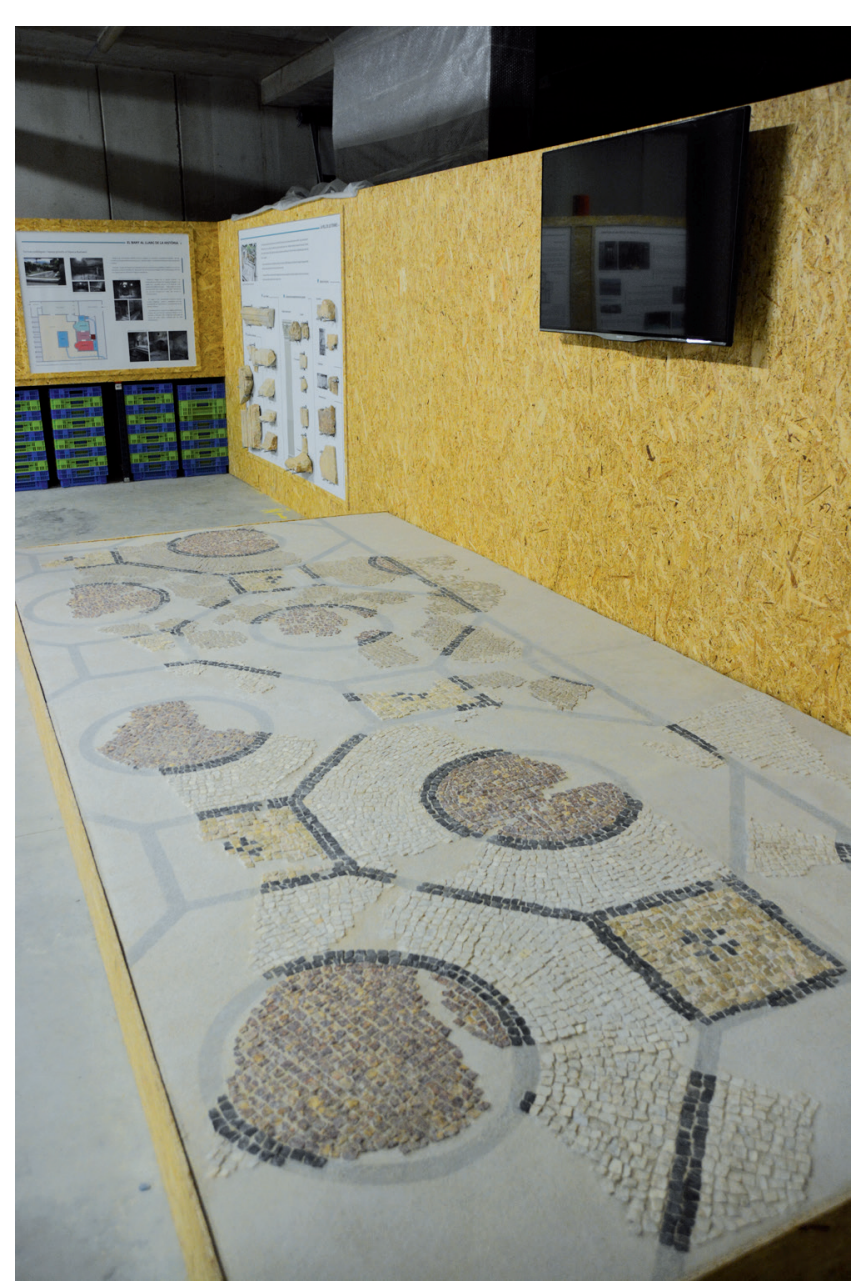

Figura 5. Mosaic exposat al magatzem de l'Arxiu Arqueològic, recuperat a les termes romanes d'Ilerda. Segle II dC. han estat considerades com a peces museitzables i per tant han estat restaurades pel SCT-Laboratori d'Arqueologia de la Universitat de Lleida, gràcies al conveni vigent sobre la matèria entre l'Ajuntament i la Universitat.

Un altre apartat temàtic el configuren els plànols de la ciutat de Lleida en les seves diverses èpoques històriques: la Ilerda romana, la medina Larida andalusina, la Leyda feudal, la Lleida moderna i contemporània. A partir de la informació recollida a les intervencions realitzades al nucli urbà s'ha elaborat un plànol 3D que reflecteix com era la ciutat en cadascun dels períodes històrics.

Les restes d'una columna del convent de Sant Francesc, recuperada en l'excavació prèvia a la construcció del pàrquing de la plaça Ricard Vinyes, obren la porta al món dels ordes religiosos a la ciutat de Lleida. Un panell ens mostra la seva distribució fora de la ciutat en època feudal i dins de les muralles en època moderna i un altre fa un petit resum de la història d'aquests ordes que des d'inicis de l'època feudal es van establir a la ciutat.

I seguint amb la línia argumental del món religiós i espiritual, l'exposició continua amb el tema de la mort, on es poden veure elements que assenyalen les tombes en diferents èpoques com l'estela discoïdal recuperada a l'excavació de la necròpolis de Sant Martí o un dels esquelets que formava part de les sis inhumacions amb cista d'època tardoromana localitzades a l'excavació de l'Antic Portal de Magdalena, elements que permeten reflexionar sobre la ubicació de les necròpolis de la ciutat al llarg de la seva història.

En l'últim tram de la mostra es presenten ordenats cronològicament els elements arquitectònics més representatius dels que es guarden al magatzem arqueològic. Entre capitells, fragments de columnes i elements policromats destaquen un finestral gòtic de guix i les claus de volta del palau reial de la Suda, que un cop restaurades van deixar veure la seva delicada policromia.

Una mostra dels materials més delicats com peces de vidre, os o cuir, que necessiten condicions especials d'humitat i temperatura i per tant no poden ser exhibits al magatzem, es pot veure en un audiovisual que tanca l'espai del magatzem adaptat per a la seva vista.

Per finalitzar la visita s'ofereix un passeig per la zona de magatzem pròpiament dita, on es pot veure el sistema d'emmagatzematge que, associat a una base de dades informatitzada, permet la localització de qualsevol material recuperat en les més de trescentes intervencions arqueològiques realitzades. I en un dels passadissos es permet als visitants sospesar una de les moltes bales de canó que van destruir el barri de Magdalena durant el conflicte bèl-lic de la Guerra de Successió a inicis del segle XvIII.

La visita al magatzem d'arqueologia està oberta al públic de totes les edats i en cas que acudeixin nens, poden realitzar algunes de les activitats dels tallers que es fan per a les escoles com el remuntatge de peces ceràmiques o l'elaboració d'un petit mosaic. 


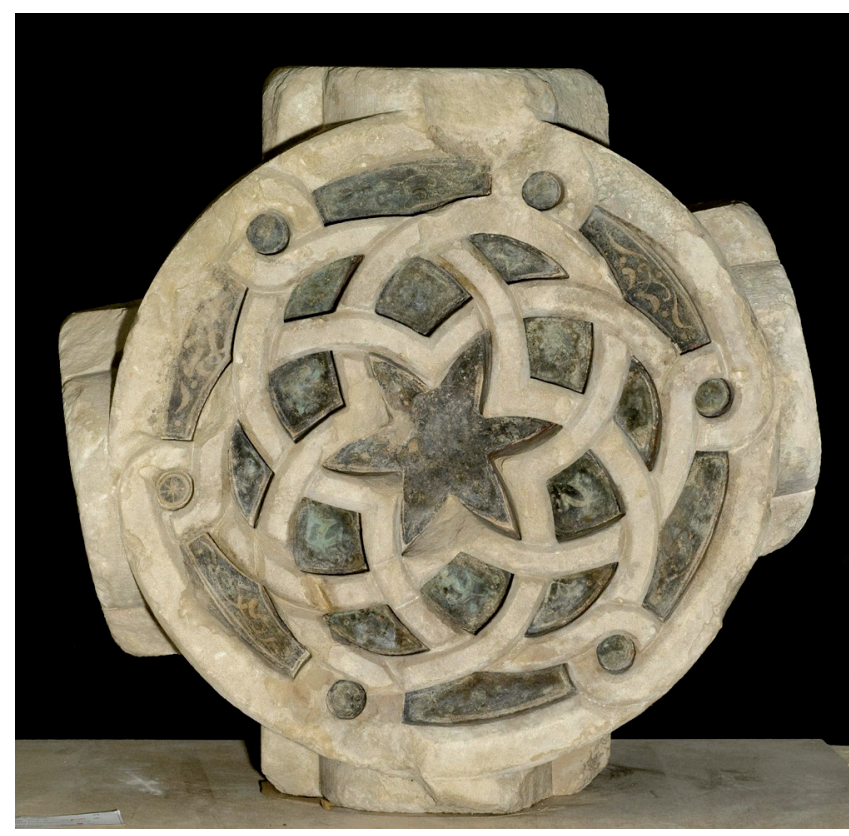

Figura 6. Clau de volta del palau reial de la Suda. Segle xIII (X. Goñi, Servei de reproducció de la imatge de la UdL).

\section{Les activitats didàctiques per a escolars}

La disciplina arqueològica ha ampliat el seu àmbit d'actuació, sobretot pel que fa a les tasques de difusió, buscant la connexió amb la pràctica educativa. En aquest context la Secció d'Arqueologia es va sumar des dels seus inicis a les ofertes didàctiques en l'àmbit educatiu no formal que volen aprofitar la didàctica de l'arqueologia per complementar les competències bàsiques dels àmbits curriculars dels diferents nivells del sistema educatiu.

Entre els anys 1995 i 2000, durant els mesos de març, abril i maig, en col-laboració amb l'Institut de Ciències de l'Educació de la Universitat de Lleida i sota el concepte general de ciutat educadora, es va dur a terme el programa de visites i recorreguts "Descobrim la ciutat oculta. Arqueologia i patrimoni de la Suda".

Entre els objectius d'aquest programa, dirigit i adaptat al cicle superior de primària, l'ESO i batxillerat, en destacaven dos. La comprensió de la història de la ciutat a partir d'un exemple concret: l'evolució històrica del Turó de la Seu Vella permet conèixer les principals etapes històriques de la ciutat i se'n pot veure l'evolució al llarg del temps. I el segon, presentar el procés arqueològic, des de l'excavació fins a la seva interpretació i arxiu com un instrument de reconstrucció de la història a partir de la recuperació i la interpretació de les restes del passat.

La valoració que en van fer els centres participants amb més de 2.000 alumnes fou positiva, els nens van conèixer el seu passat $i$ van prendre consciència de l'aportació de l'arqueologia en el coneixement de l'evolució històrica de la ciutat.

Per altra banda, des de l'any 2012 l'Arxiu Arqueològic dins del programa educatiu municipal "Educació a l'abast" ofereix a la població escolar de la ciutat diverses activitats didàctiques:

\section{"Visites guiades a les adoberies"}

Com assenyalàvem anteriorment, l'any 2010 les adoberies van ser obertes al públic, i des d'aleshores es van oferir activitats didàctiques adreçades a les escoles i IES de la ciutat. Els dos primers anys van ser gestionades des del Pla de Barris MagdalenaNoguerola, i a partir de 2012 van ser assumides per l'Arxiu Arqueològic.

Lactivitat consisteix en una visita guiada, adaptada als diferents cicles de primària, secundària i batxillerat.

Durant el recorregut per les adoberies una arqueòloga introdueix els alumnes més petits en conceptes bàsics per comprendre com funcionava una adoberia, quin tipus de pells s'utilitzaven i quins objectes es fabricaven amb les pells adobades. Als alumnes de cicles superiors a més a més se'ls expliquen els diferents processos del treball de la pell i les diverses especialitzacions segons els gremis. Al final de cada visita s'entrega als alumnes un dossier didàctic de treball que han de resoldre posteriorment a classe amb l'objectiu de reforçar i aprofundir en els continguts apresos.

\section{"Arqueòlegs, detectius del passat"}

Aquest taller, adreçat i adaptat al cicle superior de primària i 1r de l'ESO, es va dissenyar perseguint tres objectius:

- Apropar a l'alumne el treball de l'arqueòleg tant en l'aspecte d'excavació com dels treballs de laboratori posteriors: la classificació, la datació, la restauració i la interpretació. Amb la introducció de les particularitats de l'arqueologia urbana, com la que duen a terme els arqueòlegs de l'Ajuntament.

- Donar a conèixer les principals etapes històriques de la ciutat i veure'n l'evolució urbanística.

- Descobrir que els objectes que es recuperen a les excavacions arqueològiques a més de donar informació sobre les societats que els van crear i utilitzar són un element de datació.

Per assolir aquests objectius l'activitat s'ha organitzat en tres blocs:

Un primer bloc teòric, d'entre 20 i 30 minuts, en què amb ajuda d'una presentació digital, adaptada, comentada i ampliada per un arqueòleg s'explica tant als alumnes de primària con als de secundària la feina de l'arqueòleg, i en un segon apartat només per als de 1r de l'ESO es profunditza sobre el concepte d'estratigrafia arqueològica i s'explica com s'elabora la matrix d'una excavació, que després hauran de resoldre en el taller pràctic.

En el taller pràctic, tots els alumnes, treballant en parelles, fan una activitat de 30 minuts aproximadament, organitzada al voltant d'una graella on a partir de les fases històriques que es van documentar a l'excavació de l'auditori i de les pistes que ofereix l'arqueòleg han de completar tres columnes:

1. Quines són les èpoques de la història de la ciutat i conèixer com era en cada moment. S'utilitzen sis plànols que han d'ordenar des de l'època ibèrica fins a l'actualitat.

2. Classificar fragments de ceràmica trobats en excavacions de Lleida i ordenar-los en les èpoques corresponents. Els nens poden tocar materials 


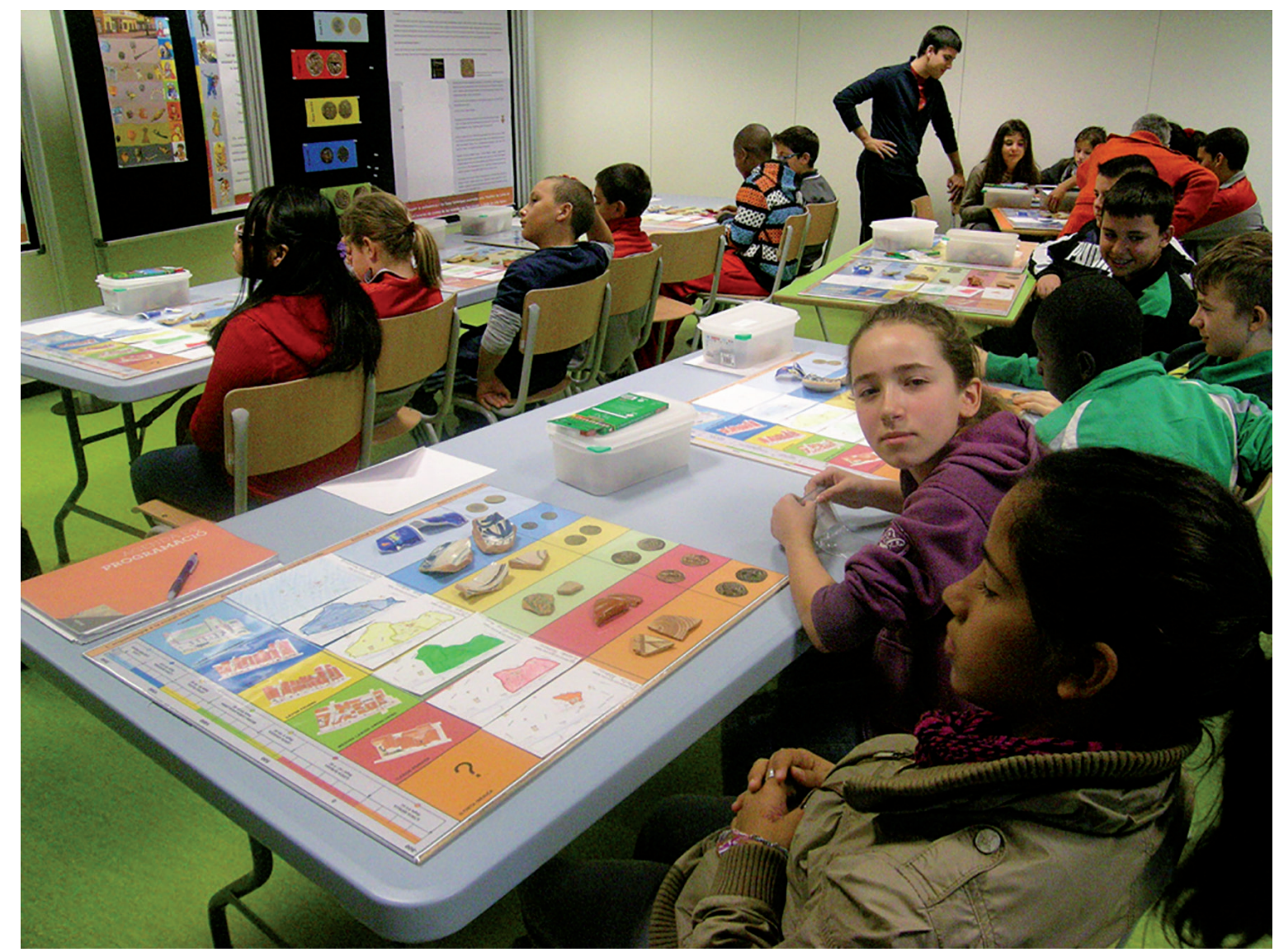

Figura 7. Graella utilitzada en el taller "Arqueòlegs, detectius del passat". Alumnes de 6è de primària del CEIP Terres de Ponent, Lleida. Curs 2012/2013.

autèntics i reconèixer les diferències que els estris utilitzats a la cuina i a la taula han tingut en cada moment de la història de Lleida.

3. Classificar les monedes que s'han encunyat a Lleida al llarg de la història. En aquest cas el material didàctic utilitzat són reproduccions.

Els alumnes de primer de l'ESO fan una segona activitat d'uns 20 minuts de durada, en què han de resoldre una matrix amb el reconeixement dels diferents estrats que el configuren i el seu ordre cronològic, seguint la metodologia treballada en la presentació. La pràctica es realitza de manera individualitzada i després es corregeix en grup.

El tercer bloc de l'activitat es du a terme al magatzem de l'arxiu, amb la visita a la zona adaptada didàcticament. Aquí, els nens poden veure, relacionar i identificar els tipus ceràmics estudiats i manipulats en el taller amb peces senceres i restaurades exposades en les vitrines.

Veuran també un mosaic romà, i gràcies a l'audiovisual amb la restitució 3D de les termes romanes d'Ilerda descobriran d'on prové i com era un dels edificis millor coneguts del nostre passat romà gràcies als treballs d'excavació realitzats en els darrers anys.

Un curt passeig pels passadissos on es guarden, en caixes paletitzades, els objectes trobats en les excavacions de Lleida permet explicar el sistema d'emmagatzematge dels objectes dels nostres avantpassats.

El recorregut acaba amb una experiència tàctil per als nens. Poden agafar amb les mans les bales de canó que l'any 1707 van destruir el barri de la Magdalena. Com que hem treballat al taller l'evolució històrica de la ciutat, recordem el plànol de la ciutat del segle XVIII on el perímetre emmurallat i la superfície de la ciutat s'havia reduït considerablement fruit dels esdeveniments bèl-lics. Ara, una part responsable d'aquells fets està entre les seves mans.

En el cas que acudeixin a fer l'activitat dos grups de manera simultània, es realitza el bloc teòric conjuntament, i després es divideixen en dos grups, i mentre el primer grup realitza el taller, el segon grup baixa al magatzem de l'arxiu a fer un joc de pistes anomenat "Descobreix els tresors de l'Arxiu Arqueològic" que d'una manera lúdica pretén que els nens visitin la zona didàctica del magatzem i descobreixin alguns dels objectes més significatius que s'hi guarden.

\section{"Afrania, una esclava d'Ilerda"}

Activitat adreçada a alumnes de l'ESO i batxillerat en què s'explica com era la ciutat romana d'Ilerda. L'objectiu principal és que els alumnes puguin identificar en la ciutat actual l'antiga forma urbis de la Ilerda romana i la localització dels seus principals edificis i espais descoberts en les excavacions arqueològiques d'aquests darrers anys.

En els grups d'humanitats de 4t d'ESO i 1r de batxillerat la presentació teòrica del tema s'amplia amb un repàs de les fonts escrites clàssiques que ens parlen d'Ilerda (Titus Livi, Cèsar, Ovidi, etc.) 


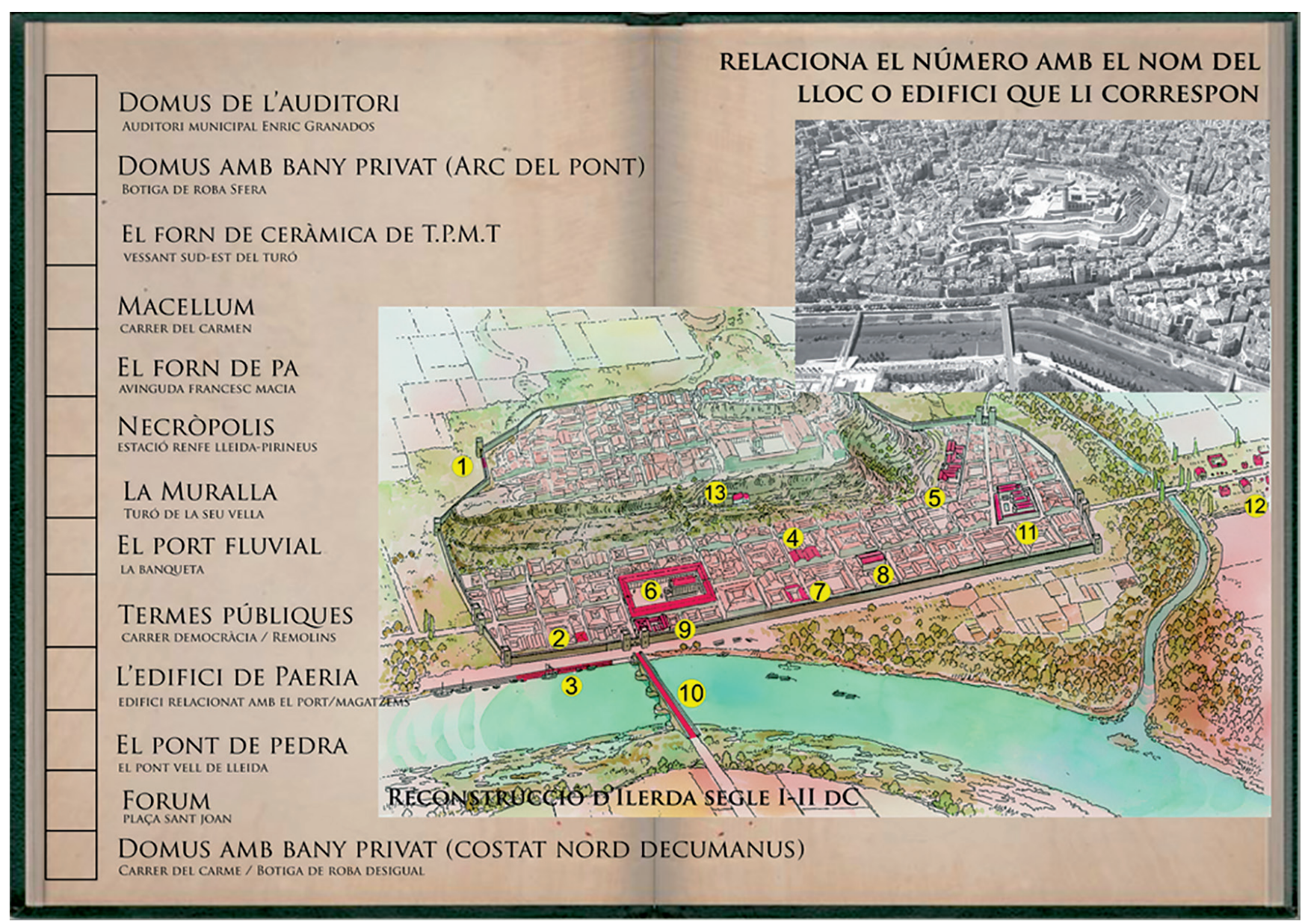

Figura 8. Exemple d'una de les fitxes utilitzades en l'activitat d'Afrania.

S'afegeix al coneixement arqueològic aquestes dades literàries, que per escasses i poc rellevants que siguin, permeten motivar els alumnes i introduir-los en la traducció de textos clàssics, una competència que forma part del contingut curricular del batxillerat d'humanitats.

Lactivitat consta de tres blocs que es desenvolupen en tres espais diferenciats:

La visualització d'un audiovisual on un arqueòleg de l'arxiu explica qui va ser Afrania, una esclava que va viure al segle II $\mathrm{dC}$, i com era la seva ciutat. Durant la presentació s'alterna la part teòrica amb la pràctica, fent diverses parades per completar les fitxes relacionades amb les competències explicades.

Les fitxes comunes a tots els grups són les relacionades amb la identificació espacial de la ciutat $\mathrm{i}$ els edificis coneguts d'Ilerda en el plànol de la ciutat actual. Mentre que les fitxes específiques de 4t ESO i batxillerat estan relacionades amb transcripcions i traduccions de làpides en llatí.

Un cop acabada la presentació i treballades les diferents fitxes del taller es realitzarà una visita al magatzem de l'arxiu. Allí, els alumnes poden veure diferents objectes d'època romana trobats a la ciutat d'Ilerda, on destaca el mosaic recuperat a les termes romanes, i visualitzaran l'audiovisual que explica aquest edifici termal descobert al carrer Cardenal Remolins explicat en primera persona per una narradora de nom Atilia que va viure al segle II. A més, a través dels marbres trobats i exposats que revestien les parets d'aquest singular edifici es fa una petita reflexió sobre l'aportació dels romans a la història de l'arquitectura.

La visita a l'arxiu finalitza amb la realització d'un puzle de vint peces amb la imatge que restitueix en 3D la volumetria de les termes romanes que han visualitzat en l'audiovisual i que es poden emportar a casa.

De manera opcional, es pot combinar aquesta activitat amb un recorregut urbà per les restes romanes conservades a la ciutat, que permet veure el tram de la muralla tardorepublicana d'Ilerda localitzada al Turó de la Seu Vella i una visita a les restes de la domus romana que hi ha al soterrani de l'Auditori Municipal Enric Granados.

\section{"Vine i faràs d'arqueòleg"}

Els objectius d'aquest taller de simulació són similars als que es volen assolir amb l'activitat "Arqueòlegs, detectius del passat":

- Entendre quin és l'objectiu d'un arqueòleg i per a què serveix l'arqueologia.

- L'adquisició i comprensió del concepte "pas del temps" treballant les diferents èpoques de la història de Lleida: ibèrica, romana, andalusina, feudal i moderna.

En aquest cas, com que el taller està adreçat a nens més petits, del cicle mitjà de primària, té un caràcter més lúdic. 


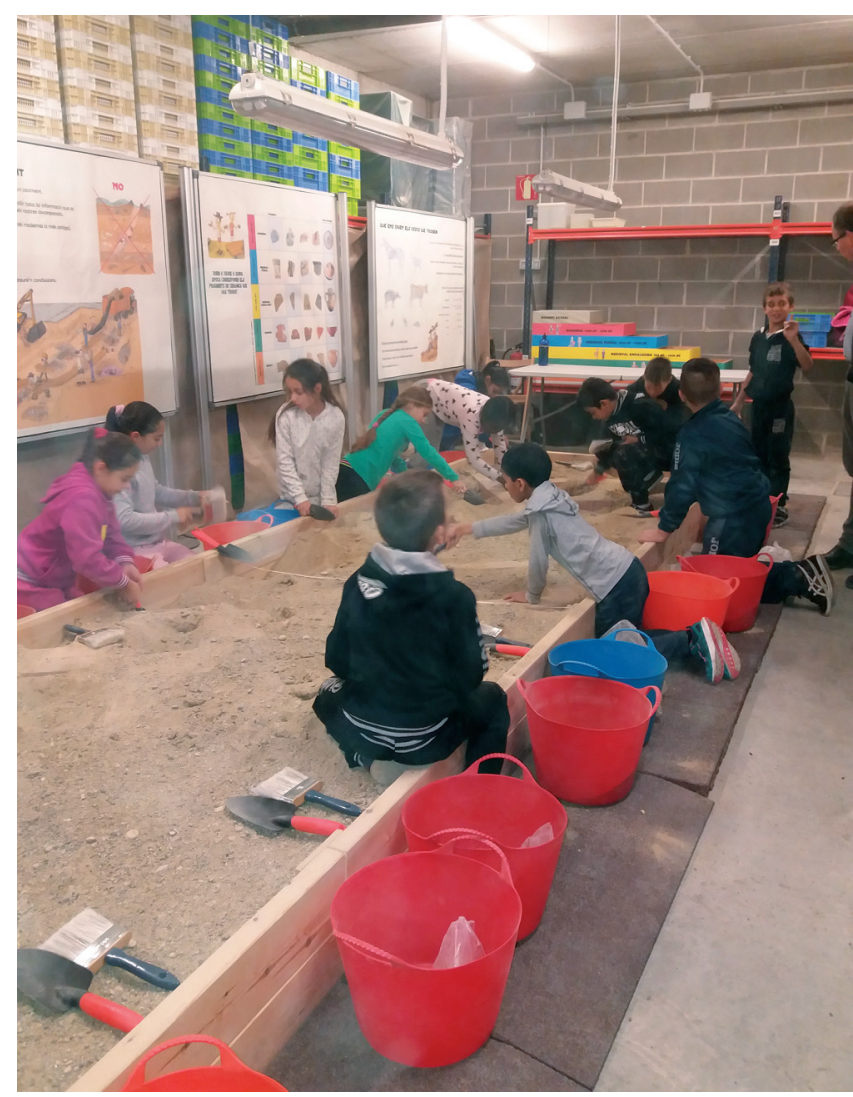

Figura 9. Excavació del sorral. Alumnes de 3r i 4t del col-legi Cervantes de Lleida. Curs 2016/2017.

El taller es divideix en dos blocs. Quan arriba el grup d'escolars, que donada la ràtio actual de les escoles oscil.la entre els vint-i-cinc i trenta alumnes, es fan dos grups, i cadascun realitza un dels dos blocs de l'activitat que duren aproximadament una hora, es fa una pausa de 30 minuts per esmorzar i s'intercanvien els grups.
El primer bloc correspon a l'excavació d'un sorral de $9 \mathrm{~m}^{2}$ on trobaran fragments de ceràmiques, ossos, monedes i restes constructives de diferents èpoques. El treball en equip esdevé una actitud imprescindible per completar amb èxit l'excavació del sorral amb l'extracció i transport de la terra i neteja de l'excavació fins a deixar a la vista les construccions (cases, carrers, església) que s'amaguen en el fons del jaciment.

Tot seguit es posaran en comú els objectes trobats entre la sorra per tal de fer una classificació temporal (de més antic a més modern) i es farà una petita interpretació de les restes descobertes.

Mentre es du a terme l'excavació del sorral l'altre grup realitza altres activitats. En un espai localitzat al costat del mosaic exposat de les termes romanes, i després de visualitzar l'audiovisual amb la restitució en 3D dels banys públics romans, els alumnes elaboren individualment amb tessel.les imantades un dels setze fragments d'un mosaic.

Un cop s'ha completat l'activitat del mosaic es dirigeixen al taller de restauració on trobaran diverses peces de vaixella de taula trencades en fragments imantats que hauran d'unir fins a completar la forma sencera.

I finalment fan un petit recorregut per la zona expositiva del magatzem, on la presència d'un esquelet d'època tardoromana recuperat a l'excavació de l'auditori i les bales de canó, que esmentàvem anteriorment, són els elements que més criden l'atenció.

La valoració d'aquests cinc anys d'activitat divulgativa duta a terme des de l'Arxiu Arqueològic de Lleida és força positiva si tenim en compte l'evolució del nombre d'assistents a les jornades de portes obertes a les restes arqueològiques i d'alumnes participants en els diferents tallers arqueològics que han augmentat progressivament cada any fins arribar als més de 1.800 visitants i 1.200 escolars el passat any 2016 .

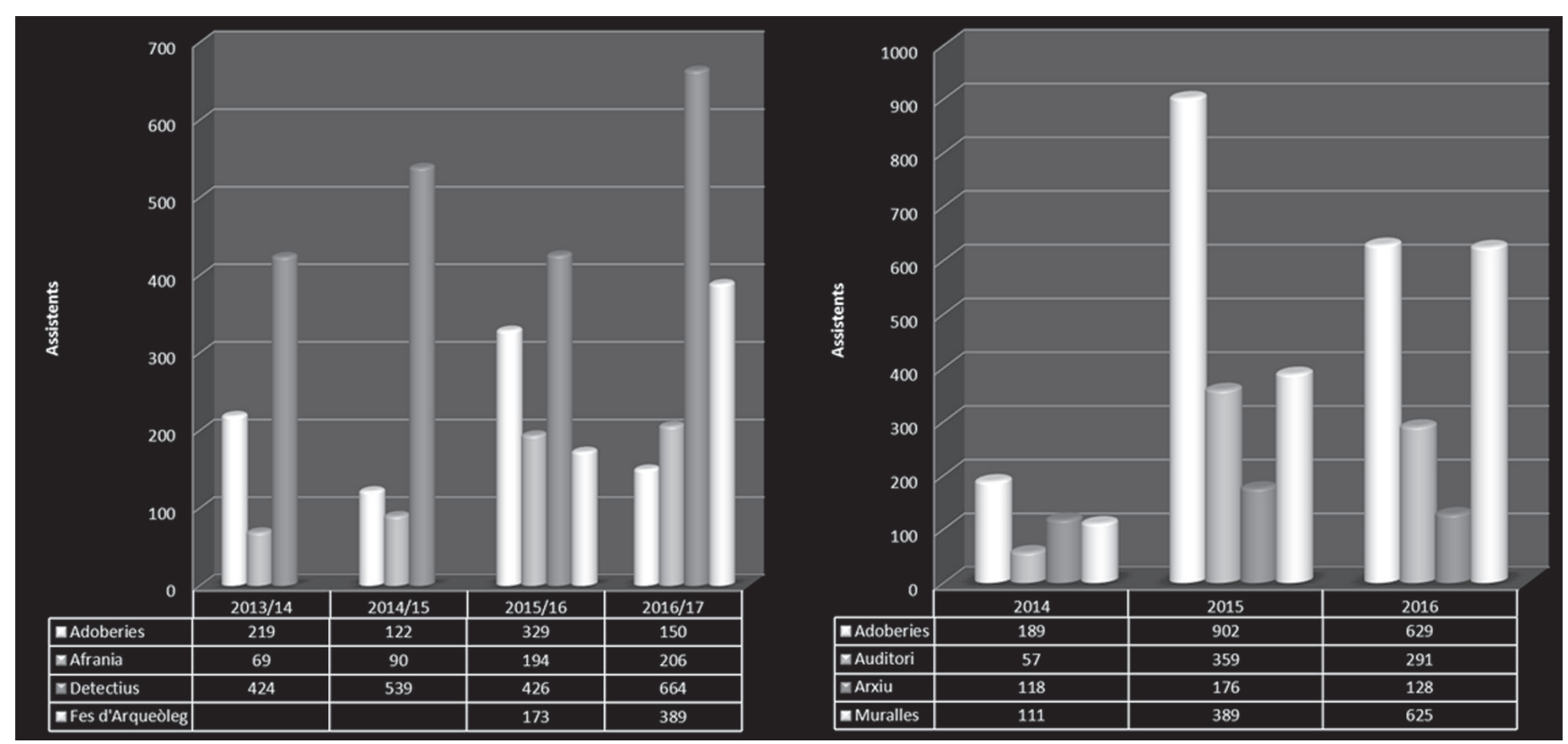

Figura 10. Gràfics de l'evolució dels assistents a les jornades de portes obertes a les restes arqueològiques des de l'any 2014 i de l'evolució dels alumnes que han realitzat les visites i tallers des del curs acadèmic 2012/2013. 
Queda sens dubte un gran camí per recórrer en la tasca d'apropar el patrimoni arqueològic de la ciutat a la població escolar i al públic en general. A l'espera de la creació d'un museu d'història de la ciutat de Lleida, amb un espai específic i recursos econòmics i humans propis, que canalitzi les activitats de difusió, l'Arxiu Arqueològic, en la mesura de les seves possibilitats, hi continuarà contribuint.
Isabel Gil Gabernet Arqueòloga de l'Arxiu Arqueològic Secció d'Arqueologia de l'Ajuntament de Lleida Avinguda Fontanet, 26 25001 Lleida $973222641 / 619400549$

\section{Bibliografia}

Badia T., Font, M. A., Loriente, A. i Pastó, C. (1998). "Descobrim la ciutat oculta. Arqueologia i patrimoni de la Suda" un programa dirigido a la difusión de la arqueología y el patrimonio de la Ciudad. Revista d'Arqueologia de Ponent, 8: 167-172.

Brown, D. H. (2007). Archaeological Archives. A guide to best practice in creation, compilation, transfer and curation. [Consultat l'11 de novembre de 2016]. Disponible a internet: <http://www.archaeologists.net/ sites/default/files/ifa_practice_archives.pdf $>$.

CACHedA, M. (2010). Guia de les activitats didàctiques a les adoberies de Lleida. [Consultat l'1 de novembre de 2016]. Disponible a internet: <http://lesadoberiesdelleida.blogspot.com.es/p/activitats-escolars.html>.

Coma, L. i Santacana, J. (2010). Ciudad educadora y patrimonio. Cookbook of heritage. Editorial Trea. Gijón.

EdwARDS, R. (2012). Archaeological archives and museums. [Consultat el 22 d'octubre de 2016] Disponible a internet: <http://archaeologydataservice.ac.uk/ archiveDS/archiveDownload? $\mathrm{t}=$ arch-381-1/dissemination/pdf/2012/1001589_Archaeological-archives-andmuseums-2012.pdf $>$.

Gallart, J., Junyent, E., Pérez, A. i Rafel, N. (1985). L'arqueologia a la ciutat de Lleida 1975-1985. Quaderns de divulgació ciutadana, Col-lecció la Banqueta, 5. Lleida.

Loriente, A. (1990). Arqueologia i difusió, una activitat i una eina que permeten comprendre la nostra història. L'arqueologia a la ciutat. ARTS Revista del Cercle de Belles Arts de Lleida, 14: 28-31.

Loriente, A. i Payà, X. (1998). L'excavació del Bar Clavé a Lleida: vuit segles de muralles. Revista d'Arqueologia de Ponent, 8: 197-200.

Loriente, A. i Oliver, A. (eds.) (1992). L'antic Portal de Magdalena. Monografies d'Arqueologia Urbana, 4. Lleida.

PAYÀ, X. (1998). Memòria de la intervenció arqueològica realitzada al carrer Anselm Clavé, 47 / plaça Mossèn Cinto Verdaguer (int-86, Lleida 1998). Inèdit.

PAYÀ, X. (2010). Les adoberies d'època feudal a la ciutat de Lleida. Revista d'Arqueologia de Ponent, 20: 27-92.

Pla General de Lleida. 2005-201. Text refós 2001. Aprovat gener 2003. [Consultat l'1 de novembre de 2016]. Disponible a internet: <http://urbanisme.paeria. cat/pla-general-de-lleida.html $>$. 